\title{
Reclamation monitoring in the Athabasca oil sands region of Canada using a long-term plot network
}

\author{
V.C. Hawkes LGL Limited Environmental Research Associates, Canada \\ G. Donald Donald Functional \& Applied Ecology Inc.; and Reclamation Working Group, Cumulative \\ Environmental Management Association, Canada
}

\begin{abstract}
Oil sands mine operators in the Athabasca oil sands region of northeastern Alberta are required to revegetate disturbed land to target the establishment of a self-sustaining, locally common boreal forest integrated with the surrounding area. The Cumulative Environmental Management Association (CEMA) is a non-profit, multi-stakeholder organisation based in Fort McMurray, Alberta, whose role is to produce recommendations to government regulators pertaining to the cumulative impact of oil sands development in northeastern Alberta. These recommendations include guidance documents for revegetation to forest ecosystems and a criteria and indicator framework for reclamation certification. To support the development of the guidance documents, CEMA manages a long-term plot network that includes permanent sample plots on reclaimed lands and in natural, undisturbed mature forest stands. A review of the monitoring conducted from 2000-2010 on the long-term plot network recommended modifications to the plot network to support the implementation of an adaptive management framework that would achieve an evaluation of: (1) the effectiveness of the revegetation guidance outlined in the guidance documents; (2) the physical and biological indicators identified through research initiatives as suitable measurement parameters to demonstrate that a self-sustaining, locally common boreal forest is establishing on the reclaimed lands; (3) the efficacy of management activities applied on the reclaimed lands to support the establishment of self-sustaining forests; and (4) whether reclaimed lands are achieving thresholds required to qualify for reclamation certification.
\end{abstract}

This paper presents the regulatory context for revegetation planning and outlines how modifications to the CEMA long-term plot network will support the implementation of an integrated monitoring program that will assess the efficacy of the guidance documents and the progress of current reclamation practices towards achieving the goal of establishing a self-sustaining boreal forest on reclaimed lands in the Athabasca oil sands region. An adaptive management framework incorporating a modified long-term plot network would provide an opportunity for the monitoring data to describe the ecological condition of the reclaimed lands and to define appropriate management strategies for achieving the revegetation goals.

\section{$1 \quad$ Introduction}

The primary objective of reclamation in the Athabasca oil sands region (AOSR) as specified by the Alberta Government's Environmental Protection and Enhancement Act (EPEA) Conservation and Reclamation Regulation is to return the specified land to an equivalent land capability, which means that the "ability of the land to support various land uses after conservation and reclamation is similar to the ability that existed prior to an activity being conducted on the land, but that the individual land uses will not necessarily be identical." The EPEA specifies the Duty to Reclaim (Section 137) and issuance of a reclamation certificate is dependent on completion of satisfactory conservation and reclamation in accordance with Section 137(2). Revegetation plans for reclaimed lands are developed following guidance documents, such as the Guidelines for Reclamation to Forest Vegetation in the Athabasca oil sands region 2nd Edition (Alberta Environment, 2010), which are developed by CEMA as recommendations to the Government of Alberta (Straker and Donald, 2010). As part of the EPEA operating approvals the oil sands mine operators are 
required to refer to the guidance documents in the development of the revegetation plans. The goal for revegetation is the establishment of self-sustaining, locally common boreal forest ecosystems.

To understand the ability of reclaimed landscapes in the AOSR to return to forest cover patterns and processes equivalent to pre-disturbance conditions, a Long-term Plot Network (LTPN) was established in 2000. The purpose of the LTPN is to facilitate the measurement of reclamation cover materials, vegetation and forest parameters (e.g. tree growth) and to assess changes in those parameters over time on reclaimed plots and compare the trends to those observed on natural plots. Ultimately, data from the LTPN could be used to evaluate: (1) that the guidance documents developed by CEMA are providing planning guidance that leads to the expected reclamation outcomes; (2) the physical and biological indicators identified through research initiatives as suitable measurement parameters and monitored on the LTPN demonstrate that a self-sustaining, locally common boreal forest is establishing on the reclaimed lands; (3) the efficacy of management actions taken to promote the development of reclaimed areas along trajectories that resemble successional patterns of native boreal forest ecosystems; and (4) whether reclaimed lands are achieving thresholds required to qualify for reclamation certification.

Research findings from long-term monitoring programs are often used in an adaptive management approach whereby policy and procedures are evaluated and modified based on interim results of the long term monitoring (de Souza and Batista, 2004). Long-term studies can also be informative when investigating slow-acting ecological processes (Gaines and Denny, 1993). An assessment of the LTPN in the AOSR (Hawkes et al., 2012) indicated that an LTPN may be an appropriate tool for evaluating how reclamation cover materials contribute to vegetation community development, which could result in an assessment of the success of reclaimed areas to develop into ecosystems that are functionally similar to those they are predicted to emulate. However, the assessment also identified substantive short-comings of the LTPN and recommended developing an effectiveness monitoring program for the LTPN as a component of an adaptive management framework.

This paper presents the regulatory context for revegetation planning and outlines how modifications to the LTPN will support the implementation of an integrated monitoring program that will assess the efficacy of the guidance documents and the progress of current reclamation practices towards achieving the goal of establishing a self-sustaining boreal forest on reclaimed lands in the ASOR. The paper focuses on upland reclamation areas in the AOSR with the acknowledgement that an integrated monitoring program should incorporate wetland reclamation areas as they are constructed and reclaimed in the future. The adaptive management framework incorporating the LTPN should provide an opportunity for the monitoring data to describe the ecological condition of the reclaimed lands and to define appropriate management strategies for achieving the revegetation goals.

\section{Regulatory context for reclamation of oil sands mines in northeastern Alberta}

Oil sands development is regulated by the Government of Alberta through a number of Acts and Regulations (MacKenzie et al., 2011). Reclamation is primarily regulated under the EPEA and the Public Lands Act administered by Alberta Environment and Sustainable Resource Development (AESRD). Through the EPEA approvals the Government of Alberta regulates air, water, dam safety, land conservation and reclamation, fish, wildlife and biodiversity. The approval from AESRD provides access to the land through a Mineral Surface Lease issued under the Public Lands Act. The Energy Resources Conservation Board regulates mine development including landform design and tailings management. Reclamation certification is regulated under Part 6, Section 138 of the EPEA. Oil Sands operators must demonstrate that conservation and reclamation has satisfactorily achieved the EPEA approval requirements to obtain a reclamation certificate. 


\subsection{Environmental Protection and Enhancement Act approval requirements}

Section 6 of the EPEA approvals for oil sands mines outlines the plan submission requirements for reclamation. The following description is a general summary of the plan submissions with a focus on upland reclamation requirements (i.e. additional plans are required for wetland reclamation but are not discussed below). The submission intervals are a general guideline as timelines may be adjusted with approval of the Designated Director of the EPEA approval (AESRD official).

A Mine Reclamation Plan details the operational plan for development and reclamation for the next 10 year period of operation of the plant and is submitted every three years. A Life of Mine Closure Plan outlines the most recent concepts for development and reclamation of the plant to end of mine life and is submitted approximately every five years. The EPEA approvals are renewed every 10 years and the Life of Mine Closure Plan is submitted as part of the approval renewal and once in the mid-point of the approval period. Three plans (Revegetation Plan, Forest Resource Plan and Plan for Reclamation Biodiversity) are submitted in alignment with the Mine Reclamation Plan every three years. The Revegetation Plan describes revegetation treatments for upland ecosystems. The Forest Resource Plan describes how pre-disturbance forest characteristics will be reflected in the reclamation areas and the components of a growth and yield program to monitor forest ecosystem development on reclaimed areas. A Plan for Reclamation Biodiversity outlines technologies (e.g. reclamation coversoil and revegetation treatments) required to establish best practices for the development of biodiversity for a range of target ecosystems through reclamation, and a schedule for monitoring to document the return of biodiversity in the reclaimed landscape and to compare changes in biodiversity on reclaimed sites and in the region. A Soil Placement Plan describing how salvaged reclamation materials will be used to achieve reclamation objectives is submitted annually.

\subsection{Application of CEMA guidelines in the Alberta regulatory system}

Guidance documents developed within the Reclamation Working Group of CEMA are directly referenced in the EPEA approvals issued by AESRD for the oil sands mines. This establishes a regulatory requirement that the operators follow the guidance documents in the development of the plans specified in the approval.

With respect to upland reclamation, the Guidelines for Reclamation to Forest Vegetation in the Athabasca oil sands region 2nd Edition (Alberta Environment, 2010) is used to develop or update a company's Revegetation Plan. The Land Capability Classification System for Forest Ecosystems in the Oil Sands (Alberta Environment, 2006) is used for soil placement planning and assessment and revegetation planning, and the Best Management Practices for Conservation of Reclamation Materials in the Mineable Oil Sands Region of Alberta (Alberta Environment and Water, 2012) is used in the development of Soil Placement Plans, Mine Reclamation Plans, and Life of Mine Closure Plans.

\subsection{A framework for reclamation certification criteria and indicators for mineable oil sands}

Reclamation criteria for oil sands mines are presently established through multiple means: EPEA approval conditions, CEMA guidance documents, and individual reclamation plans (Poscente and Charette, 2011). CEMA is currently developing a framework for reclamation certification for mineable oil sands to consolidate the criteria and indicators appropriate to reclamation certification. The indicators will provide a data-based evaluation of whether or not the conservation and reclamation practices have satisfactorily achieved the EPEA approval requirements. The first version of the framework is expected to be forwarded to the CEMA Board as a recommendation to the Government of Alberta and to be maintained and updated by CEMA as required. The intent of the project is to develop a common approach across all oil sands mines to:

- Track the progress of reclamation.

- Implement adaptive management actions when required.

- Determine compliance with approval conditions. 
- Assess over-all reclamation success.

The criteria and indicator approach is designed to be compatible and complementary with the EPEA Conservation and Reclamation Regulation and the reclamation certification process for oil sands mines. The framework includes two adaptive management loops. One cycle is triggered when audit or monitoring results reveal that an indicator did not achieve the threshold. The other cycle is for regular, continuous improvement of the criteria and indicator framework, which is aligned to the reclamation plans, and monitoring and research programs.

The thresholds for indicators proposed for the criteria and indicator framework are derived from either existing requirements in the EPEA approvals or CEMA guidance documents, or will be determined via research initiatives that evaluate the responsiveness of the indicator to drivers identified as components of reclamation practice that can be addressed through management actions (i.e. suitable placement of reclamation cover materials).

\section{$3 \quad$ Long-term plot network}

\subsection{History of the LTPN in the AOSR}

In 2000, the Soil and Vegetation Working Group, now the Terrestrial Sub-group of CEMA implemented the LTPN to monitor changes and long-term development of vegetation, reclamation cover material quality, and tree growth on reclaimed areas in the AOSR (Timberline, 2009). The sampling design of the LTPN includes two types of permanent sampling plots (PSPs): reclaimed and natural. Reclaimed plots are established in reclamation areas that were previously disturbed by mining activities. The reclamation procedures vary by site and with respect to reclamation cover materials and revegetation treatments. Natural plots are established in the naturally occurring and surrounding boreal forest and represent the perceived endpoint of the reclaimed sites (i.e. a self-sustaining, locally common boreal forest ecosystem). The assumption is that through reclamation, previously disturbed lands will resemble the naturally occurring and surrounding boreal forest sometime in the future. Under the program, PSPs are remeasured on reclaimed plots (at five year intervals) and on natural plots (at 10 year intervals) to monitor these characteristics.

Between five and 25 plots were established in natural stands each year between 2000 and 2004 and between one and 22 reclaimed plots were added each year between 2000 and 2009. In general, less than 10 plots of either type were added each year with the exception of 2002 when $>20$ plots of each type were added. Because of the challenges associated with working in an ever-changing environment and due to changing reclamation practices, some of the plots in the LTPN have either been damaged or become obsolete. At the end of 2010 there were 46 natural plots and 63 reclaimed sites remaining in the LTPN (Figure 1).

\subsection{Assessment of current status of the long-term plot network}

Hawkes et al. (2012) assessed the sampling design and dataset of the LTPN to determine if the LTPN could be used to assess the three previously defined objectives of the LTPN: (1) to monitor plant community structure and composition on reclaimed sites and compare over time with reference conditions at an appropriate scale; (2) to monitor properties and functions of reclamation cover materials on reclaimed sites to support receptor establishment and development on reclaimed sites; and (3) to develop a dataset to express trends that will suggest which items require further examination to provide the backbone for potential future research. 


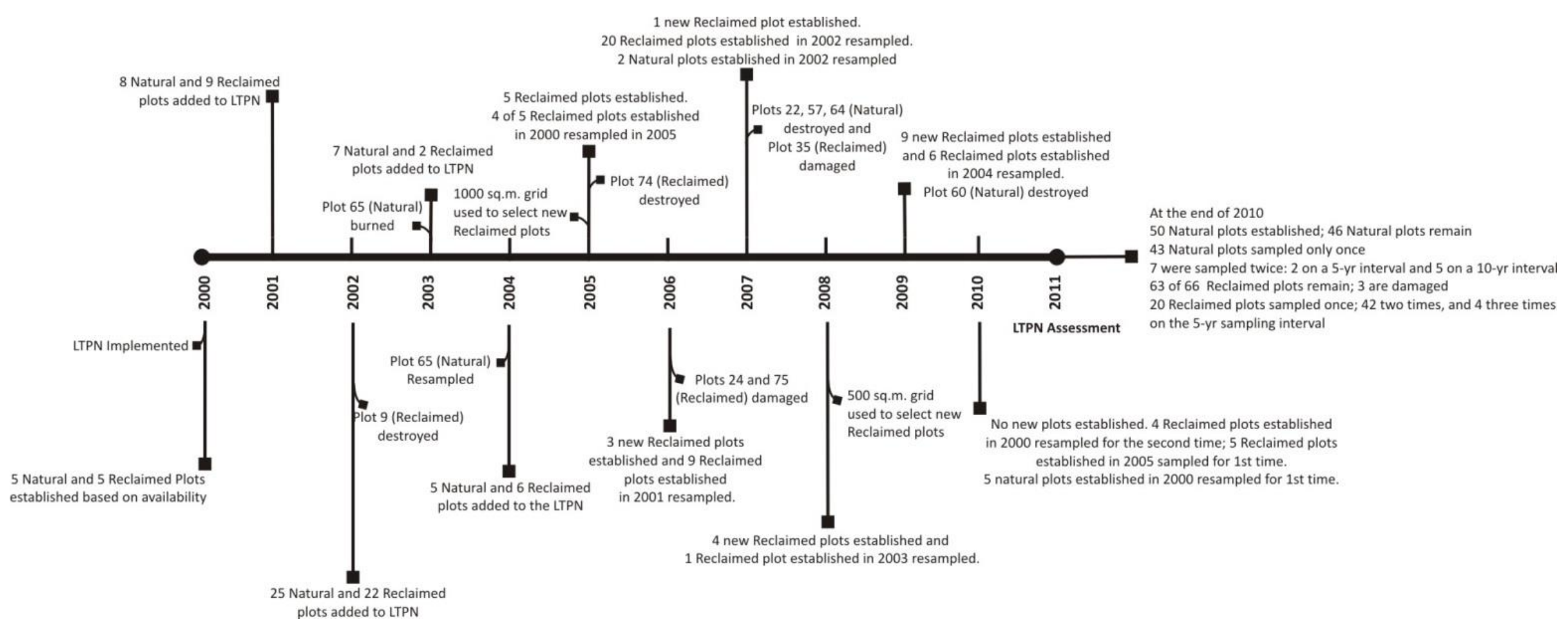

Figure 1 Timeline of the LTPN depicting major events associated with LTPN implementation, plot establishment and sampling, and significant events related to the plots 
The assessment identified several shortcomings of the sampling design and dataset of the LTPN limiting the capacity of the LTPN to address the objectives. Some examples of the shortcomings include:

- No target declaration for reclaimed plots established in reclamation areas prior to and including 2009, which limits the evaluation of the first objective because the appropriate natural plots for comparison of reclaimed plots are uncertain (i.e. unknown target declaration therefore appropriate reference site to compare the reclaimed site is uncertain). As of 2010, based on the guidance in the Guidelines for Reclamation to Forest Vegetation in the Athabasca oil sands region 2nd Edition (Alberta Environment, 2010) the target for each reclamation area must be declared.

- Inappropriate reference sites (i.e. establishment of natural plots in mature forest stands). The natural plots in the LTPN are located in mature natural stands, which affects the evaluation of the first objective because reclamation areas ranging from year zero to approximately 30 years old are compared to natural plots ranging in age from approximately 50-120 years old. Reclaimed plots should be compared to natural plots representing similar stages of development (i.e. young seral through climax stands, as reclamation areas develop) to document the range of conditions over which natural vegetation communities occur and determine if reclaimed plots are developing on a similar trajectory.

- Limited documentation of revegetation treatments (e.g. overstorey planting densities, understorey planting practices, tree stock) and management activities (e.g. use of nurse crops, frequency of infill planting, fertilisation practices) applied to reclamation areas. The dataset of the LTPN does not currently include detailed information of revegetation treatments or management activities applied to the reclamation areas, which affects the evaluation of the second objective.

- Sampling design and frequency (five year re-measurement cycle for reclaimed plots) limits the development of a dataset to express trends and identify items, which requires further examination. An intensified sampling grid and sampling frequency would support development of a dataset for trend analysis.

Based on their assessment, Hawkes et al. (2012) proposed that the LTPN should be defined as an effectiveness monitoring program incorporated into an adaptive management framework. Effectiveness monitoring could be implemented to determine if the guidance developed by CEMA is achieving the desired reclamation outcomes. The LTPN provides an opportunity to evaluate the guidance developed by CEMA and to use the results to revise and update the guidance documents to better inform reclamation planning, implementation, and/or evaluation. In this way, the LTPN would become a critical component of an adaptive management framework for reclamation activities in the AOSR (Taylor et al., 1997; Morrison, 2001; Machmer and Steeger, 2002).

The total mineable oil sands area is estimated to be $4,800 \mathrm{~km}^{2}$ (Government of Alberta, 2010). The total active footprint (i.e. disturbance) for all oil sands mining activities as of December 31, 2010 was $714.9 \mathrm{~km}^{2}$ ( $\sim 15 \%$ of the total mineable area; Government of Alberta, 2010). Of the total disturbance, $48.6 \mathrm{~km}^{2}(\sim 7 \%)$ are designated as permanent reclamation. Data from the LTPN needs to inform on the effectiveness of the guidance followed to implement permanent reclamation and on the performance of the reclamation outcomes achieved. The results of the LTPN could feed into an adaptive management framework to inform practices for the remaining existing disturbance $\left(665.6 \mathrm{~km}^{2}\right)$ and future disturbances (six mines are in the early stages of development, one mine has regulatory approval but has not commenced construction or operation, one mine is in the regulatory approval review period, and one mine has yet to apply for regulatory approval). Given the scale of disturbance planned or likely to occur in this region of Alberta and that approval of projects is based on predictions that reclamation will mitigate the environmental effects of this disturbance, evaluation of existing reclamation outcomes is critical to ensuring reclamation successfully re-establishes self-sustaining, native boreal forest ecosystems. 


\section{$4 \quad$ Recommendation to support an integrated monitoring program}

\subsection{Implement an adaptive management framework}

The adaptive management framework proposed by Hawkes et al. (2012) is based on the model for largescale ecosystem restoration recommended by the Society for Ecosystem Restoration (2004) which includes interdisciplinary science, planning and engineering as fundamental components of a comprehensive adaptive management framework. Figure 2 demonstrates how the proposed adaptive management framework with an embedded effectiveness monitoring program would enable CEMA to evaluate whether the guidance documents are leading to the intended reclamation outcomes. In this example, an environmental impact assessment, which contains the first conceptual conservation and reclamation plan for a proposed development receives regulatory approval. As part of the EPEA approvals, Life of Mine Closure Plans, Mine Reclamation Plans and Revegetation Plans are prepared using guidance documents developed by CEMA and submitted at defined intervals throughout the operating life of a project (See Section 2.1). Based on these plans reclamation practices are implemented to mitigate for habitat disturbance and the efficacy of the guidance supporting the plan development and defining the reclamation practices is assessed via an effectiveness monitoring program. Data collected via an LTPN are assessed for trends and if those trends suggest that the goals of the reclamation plans are being met then guidance for reclamation will be considered appropriate. If those trends suggest that the reclaimed habitats are not developing along a trajectory towards the naturally occurring surrounding boreal forest, then adjustments to either the reclamation guidance or the effectiveness monitoring program (or both) are required. Changes to the monitoring program may be required to ensure that data collected from the LTPN are sufficient for assessing trends. This is indicated via the adaptive management feedback loop that feeds information back to the habitat reclamation, effectiveness monitoring, and environmental impacts assessment components of operations in the AOSR. For CEMA, the data would support an evaluation of the guidance documents and whether or not the guidance is leading to the intended outcomes as proposed in the plans. CEMA would disseminate the information to its members and the public on an annual basis through an annual reporting process.

To be defined and implemented as an effectiveness monitoring program and a component of an adaptive management framework, the LTPN requires the development of project-specific objectives that are addressed by answering management questions. Hypotheses need to be formulated to test the management questions. Clear management questions should be developed for the LTPN that can be used to address the stated objectives. The development of a series of management questions will direct sampling on the LTPN and narrow the focus of data collection, analyses, and interpretation. CEMA could consider how the guidance developed by CEMA and the LTPN align with the key characteristics of adaptive management (Table 1).

Currently the incorporation of the LTPN into an adaptive management framework is limited by the availability of historical data for revegetation treatments and management activities applied to existing reclamation areas. In 2010, a geodatabase was developed by the Government of Alberta (Bampfylde et al., 2010) and operators are now required to submit spatial data documenting revegetation treatments and management activities for all reclamation areas as part of their annual conservation and reclamation reports. Documentation of this information for existing reclamation areas (i.e. areas reclaimed prior to 2010) is in the process of being compiled and the Government of Alberta requested that these data be submitted to populate the geodatabase for all existing reclamation areas. CEMA could capitalise on the geodatabase submissions and align site description fields for reclaimed plots in the LTPN database to the regulatory reporting categories. For example, reclaimed plots in the LTPN would be described using the oil sands feature type, oil sands land cover, oil sands soils and the vegetation tracking fields in the geodatabase. The reclamation practices implemented based on the guidance would be tracked in the LTPN in alignment with the regulatory reporting requirements facilitating an assessment of the effectiveness of the guidance. The management questions defined for the LTPN could be addressed in combination with the regulatory data and the monitoring data. In this way, an evaluation of the guidance recommended by 
CEMA could be conducted and refinements to the guidance to improve practices for future reclamation could be developed and incorporated into updated versions of the guidance documents.

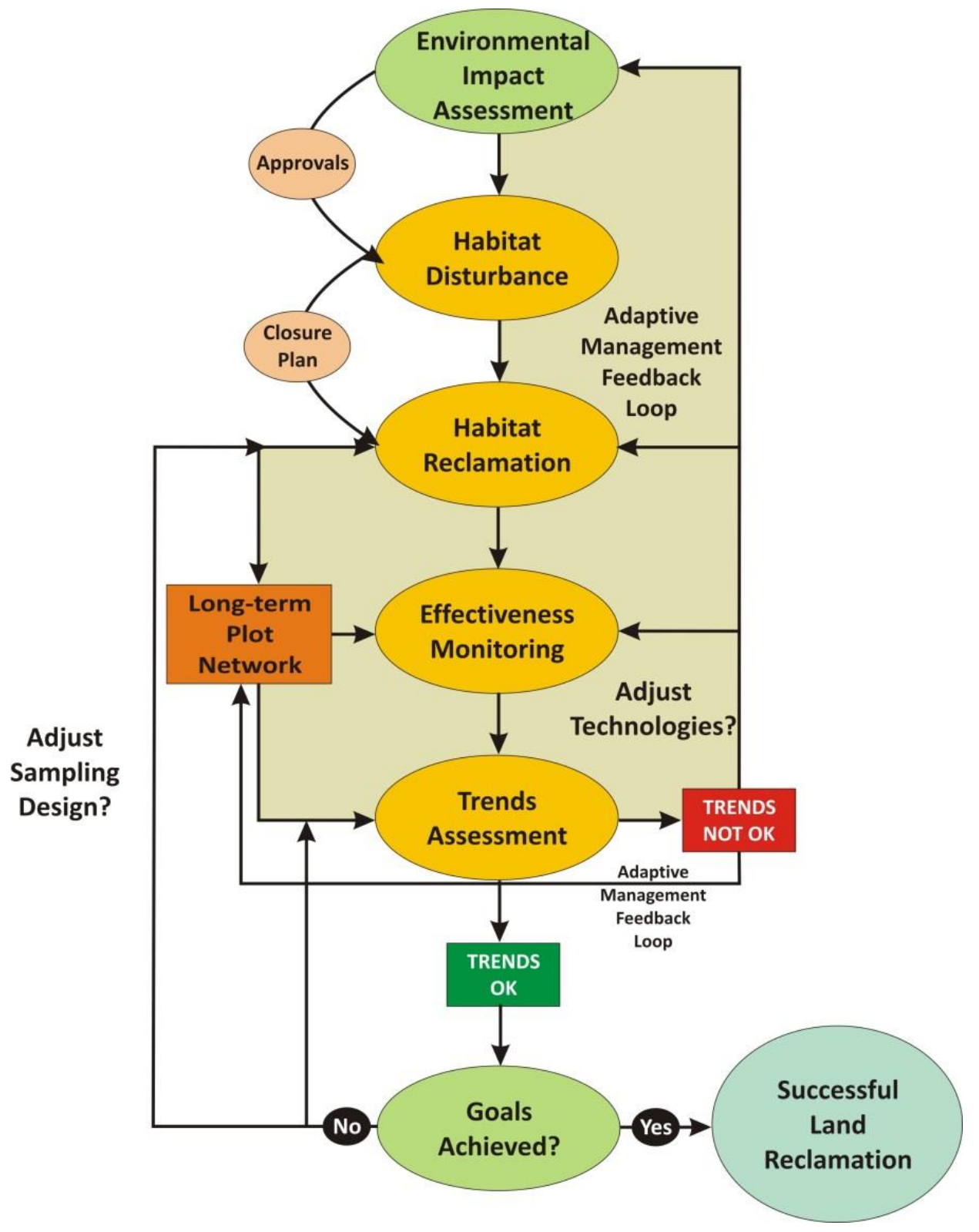

Figure 2 Schematic of an adaptive management framework for the LTPN that provides guidance based on results obtained from the LTPN that are then turned into metrics of success. The goal of the adaptive management feedback framework is to provide feedback regarding reclamation efficacy that can inform future habitat reclamation procedures and environmental impact assessments. A similar adaptive management feedback loop is associated with the LTPN to ensure that lessons learned are incorporated into future monitoring. Concept after Tongway and Ludwig (2011) (Figure from Hawkes et al., 2012) 
Table 1 Application of adaptive management in CEMA's long-term plot network

\begin{tabular}{|c|c|}
\hline Key Characteristic of Adaptive Management ${ }^{1}$ & Application to CEMA's LTPN \\
\hline $\begin{array}{l}\text { Acknowledgement of uncertainty about what } \\
\text { policy or practice is 'best' for the particular } \\
\text { management issue }\end{array}$ & $\begin{array}{l}\text { Guidance documents developed by CEMA } \\
\text { recommend current best practices and identify } \\
\text { knowledge gaps }\end{array}$ \\
\hline $\begin{array}{l}\text { Thoughtful selection of the policies or practices to } \\
\text { be applied }\end{array}$ & $\begin{array}{l}\text { EPEA approvals require operators to refer to the } \\
\text { CEMA guidance documents to develop Life of Mine } \\
\text { Closure Plans, Mine Reclamation Plans, } \\
\text { Revegetation Plans }\end{array}$ \\
\hline $\begin{array}{l}\text { Careful implementation of a plan of action } \\
\text { designed to reveal the critical knowledge }\end{array}$ & $\begin{array}{l}\text { EPEA approvals require operators to implement } \\
\text { the plans and to participate in CEMA }\end{array}$ \\
\hline Monitoring of key response indicators & CEMA monitors the reclamation areas via the LTPN \\
\hline $\begin{array}{l}\text { Analysis of the outcome in consideration of the } \\
\text { original objectives }\end{array}$ & $\begin{array}{l}\text { CEMA evaluates the data from the LTPN to } \\
\text { determine if the guidance is leading to the } \\
\text { intended outcome }\end{array}$ \\
\hline Incorporation of the results into future decisions & $\begin{array}{l}\text { CEMA revises and updates the guidance } \\
\text { documents and LTPN as required }\end{array}$ \\
\hline
\end{tabular}

1 Based on Nyberg (1998)

Adaptive management is valuable whenever there is significant uncertainty about the outcomes of management or reclamation practices (Taylor et al., 1997). The LTPN sampling design could be modified to allow CEMA to reliably evaluate the effectiveness of reclamation practices defined in the guidance documents. Those results could be used to revise the guidance documents to increase the probability of success associated with reclamation. The implementation of the proposed adaptive management framework could provide structure for the LTPN and allow CEMA to proceed systematically and responsibly in the face of uncertainty, gaps in understanding, and disagreement (Taylor et al., 1997). The LTPN could become more efficient and effective by focusing efforts on specific management questions about the development of reclaimed ecosystems based on existing guidance and reducing unnecessary collection of data that will not inform on the effectiveness of guidance documents.

\subsection{Define an integrated monitoring program}

Within the proposed adaptive management framework, in addition to evaluating the guidance developed by CEMA, long-term monitoring provides an opportunity for learning about large-scale, ecosystem-level relationships, how reclaimed ecosystems develop over time and an increased understanding of how reclaimed ecosystems function. Several research initiatives sponsored by CEMA are investigating the development of indicators for incorporation into the criteria and indicator framework for reclamation certification discussed in Section 2.3, and as technical reports supporting the development of new guidance such as the development of a state-and-transition model for reclaimed lands in the AOSR which will simulate reclamation outcomes based on current best practices and provide a tool for reclamation planning.

The indicators proposed for the criteria and indicator framework for reclamation certification will be associated with a threshold value that must be achieved on reclaimed lands to qualify for reclamation certification (Poscente and Charette, 2011). For example, the Guidelines for Reclamation to Forest Vegetation in the Athabasca oil sands region, 2nd Edition (Alberta Environment, 2010) defines characteristic species (i.e. those species typically found in the non-mined, native plant communities in the AOSR) as an indicator of reclamation success. The number of characteristic species is used to indicate if reclaimed areas are achieving plant community compositions similar to that of a natural ecosite (as per Beckingham and Archibald, 1996). The state-and-transition model identifies management activities that 
would be required to apply to reclamation areas if the characteristic species thresholds were not attained. An integrated monitoring program embedded in an adaptive management framework could evaluate the applicability of the indicators proposed for reclamation certification and test the probabilities defined for different reclamation practices in the state-and-transition model of achieving the thresholds defined for the indicators. By documenting reclamation cover soil and revegetation treatments in the LTPN dataset and identifying the management activities that are applied on reclamation areas to improve reclamation outcomes (i.e. infill planting, fertilisation, weed control), the probability of achieving the reclamation outcomes can be calibrated using data collected on the LTPN and the state-and-transition model simulations can test whether or not the guidance outlined in the CEMA guidance documents is likely to achieve the intended reclamation outcomes.

\subsection{Monitor assessment points to describe ecological condition of reclaimed lands}

Carter and Bennetts (2007) proposed an approach to integrate science and management based on using an objectives hierarchy to define an adaptive management framework and assessment points to evaluate whether or not the adaptive management framework is achieving the objectives. Based on the proposed adaptive management framework incorporating the LTPN described in Section 4.1, an effectiveness monitoring program would inform on objectives related to planning and learning. Based on Carter and Bennetts' definitions (2007), assessment points are predefined and are tools that are used to link program objectives to desired endpoints via an adaptive management framework. The assessment points in the proposed adaptive management framework incorporating the LTPN would link objectives related to planning (i.e. those related to CEMA guidance documents) and objectives related to learning (i.e. those related to monitoring and research). The assessment points link the main program areas and similar data from these areas can be used to describe the ecological condition of the study area. For CEMA, this type of approach would facilitate an integrated monitoring program for reclaimed lands.

For example, assessment points could be aligned with states identified in a state-and-transition model and the monitoring data collected to address the objectives hierarchy could be used to calibrate or validate the state-and-transition model. Figure 3 illustrates how the approach proposed by Carter and Bennetts (2007) may provide a foundation for implementing the adaptive management framework proposed in Section 4.1. Arriving at a predefined assessment point would not require immediate action - data would be used to assess what state the reclamation area is in and that state would dictate whether some form of mitigation is required or whether further research is needed to better assess the problem. By implementing the proposed adaptive management program in Section 4.1, the LTPN in the AOSR could become a fully integrated program comprised of monitoring, management, and research - all of which would address the objectives hierarchy of an adaptive management framework.

\section{Conclusions}

The implementation of an adaptive management framework as proposed in Section 4.1 should include the development of an integrated monitoring program in the AOSR. The results of the integrated monitoring program would support continuous evaluation of the guidance documents developed by CEMA. The link between science and management would be bolstered by using an objectives hierarchy to define the adaptive management framework. Assessment points identified in the adaptive management framework would inform multiple objectives of the hierarchy and provide a linkage between monitoring, management and research. In additional, several initiatives sponsored by CEMA to define indicators for reclamation certification and state-and-transition models for reclaimed landscapes would both help to define the components of a fully integrated monitoring program and be informed by the results of the integrated monitoring program. Ultimately, the adaptive management framework would support refinement of the CEMA guidance documents and assess the ecological condition of reclaimed landscapes to provide information on the ecological function and productivity of these landscapes. 


\begin{tabular}{|c|c|c|c|c|}
\hline \multirow{2}{*}{\multicolumn{2}{|c|}{ Program Focus }} & \multicolumn{3}{|c|}{ Program Areas } \\
\hline & & Monitoring & Management & Research \\
\hline \multirow{3}{*}{$\begin{array}{l}n \\
0 \\
0 \\
0 \\
0 \\
\frac{0}{0} \\
0 \\
0 \\
0 \\
0\end{array}$} & Purpose & Detect Trends & Prevent Impairment & Quantify Effects \\
\hline & Uncertainty & $\begin{array}{l}\text { Statistical } \\
\text { "Is it Real?" }\end{array}$ & $\begin{array}{c}\text { Efficacy } \\
\text { "Is it Working?" }\end{array}$ & $\begin{array}{c}\text { Causality } \\
\text { "Is it Meaningful?" }\end{array}$ \\
\hline & Rigor & Survey Design & Document Actions & Experimentation \\
\hline \multicolumn{5}{|c|}{ Single Program Area Focus } \\
\hline \multicolumn{5}{|c|}{ Multi Program Area Focus } \\
\hline Full & rogram Integrat & $\sum$ & T & () \\
\hline
\end{tabular}

Figure 3 Schematic of the relationship between program areas and their main considerations relative to a single, multi, or full program focus. Circles represent assessment points used to evaluate the various considerations of each program area. Data from each program area are used to evaluate the adequacy of the assessment points (figure modified from Carter and Bennetts, 2007)

\section{Acknowledgements}

The authors wish to acknowledge Dr David Bergstrom of Alberta Environment and Sustainable Resource Development and an anonymous reviewer for comments on an earlier version of the paper. In addition, CEMA's Reclamation Working Group provided funding for the assessment of LTPN completed by Hawkes et al. (2012).

\section{References}

Alberta Environment (2006) Land Capability Classification System for Forest Ecosystems in the Oil Sands, 3rd Edition, Vol. 1: Field Manual for Land Capability Determination, Prepared for Alberta Environment by the Cumulative Environmental Management Association, Fort McMurray, Alberta.

Alberta Environment (2010) Guidelines for Reclamation to Forest Vegetation in the Athabasca Oil Sands Region, 2nd Edition, Prepared by the Terrestrial Subgroup of the Reclamation Working Group of the Cumulative Environmental Management Association, Fort McMurray, Alberta, December 2009.

Alberta Environment and Water (2012) Best Management Practices for Conservation of Reclamation Materials in the Mineable Oil Sands Region of Alberta, Prepared by D. MacKenzie for the Terrestrial Subgroup, Best Management Practices Task Group of the Reclamation Working Group of the Cumulative Environmental Management Association, Fort McMurray, Alberta, March 9, 2012.

Bampfylde, C., Hughes, S., Page, D., Purdy, B., Stanley, S. and Syed, A. (2010) Compiling a geospatial database of existing oil sands industrial features for Alberta Environment, in Proceedings Canadian Geomatics Conference 2010, June 15-18, Calgary, Alberta.

Beckingham, J.D. and Archibald, J.H. (1996) Field guide to ecosites of Northern Alberta, Canadian Forest Service, Northwest Region, Northern Forestry Centre, Special Report 5.

Carter, S.L. and Bennetts, R.E. (2007) The road to integrating science and management: planning your next trip using hierarchical objectives and assessment points, The George Wright Forum, Vol. 24, No. 2, pp. 78-93.

de Souza, F.M. and Batista, J.L.F. (2004) Restoration of seasonal semi-deciduous forests in Brazil: influence of age and restoration design on forest structure, Forest Ecology and Management, Vol. 191 (2004), pp. 185-200.

Gaines, S.D. and Denny, M.W. (1993) The largest, smallest, highest, lowest, longest and shortest: extremes in ecology, Ecology, Vol. 74, pp. 1677-1692.

Government of Alberta (2010) Alberta's Oil Sands Reclamation, viewed 12/05/2012, http://www.oilsands.alberta.ca/reclamation.html. 
Hawkes, V.C., Muir, J.E. and Enns, K.A. (2012) Long-term Plot Network Assessment, LGL Report EA3309, Unpublished report by LGL Limited environmental research associates, Sidney, BC, for CEMA - The Reclamation Working Group (RWG), Fort McMurray, Alberta, $79 \mathrm{p}$.

Machmer, M. and Steeger, C. (2002) Effectiveness monitoring guidelines for ecosystem restoration, B.C. Ministry of Environment, Victoria, British Columbia, $18 \mathrm{p}$.

MacKenzie, D.D., Amponsah, I.G., Bergstrom D.W. and Anderson, H.B. (2011) Defining best management practices for conservation of reclamation materials in the mineable oil sands region of Alberta, in Proceedings Sixth International Conference on Mine Closure (Mine Closure 2011), A.B. Fourie, M. Tibbett and A. Beersing (eds), 19-21 September 2011, Lake Louise, Canada, Australian Centre for Geomechanics, Perth, Vol. 1, pp. 125-132.

Morrison, M.L. (2001) Introduction: concepts of wildlife and wildlife habitat for ecological restoration, Restoration Ecology, Vol. 9, pp. 251-252.

Nyberg, B. (1998) Land Management Handbook No. 42, Statistics and the practice of adaptive management, in Statistical Methods for Adaptive Management Studies, V. Sit and B. Taylor (editors), B.C. Ministry of Forests, British Columbia, pp. 1-8.

Poscente, M. and Charette, T. (2011) Criteria and Indicators Approach for Oil Sands Mine Reclamation Interim Report, Prepared for the Reclamation Working Group of the Cumulative Environmental Management Association, Fort McMurray, Alberta, July 25, 2011.

Society for Ecological Restoration (2004) The SER international primer on ecological restoration, Version 2 in Society for Ecological Restoration International Science \& Policy Working Group, Society for Ecological Restoration International, viewed 20/06/2012, http://www.ser.org/content/ecological_restoration_primer.asp

Straker, J. and Donald, G. (2010) Developing the guidelines for reclamation to forest vegetation in the Athabasca oil sands region, Unpublished report by Integral Ecology Group Ltd., Donald Functional and Applied Ecology Inc., and Terrestrial Subgroup, Reclamation Working Group, Cumulative Environmental Management Association (CEMA), British Columbia Mine Reclamation Symposium 2010, 14 p.

Taylor, B., Kremstaer, L. and Ellis, R. (1997) Adaptive Management of Forests in British Columbia, Forest Practices Branch, B.C. Ministry of Forests, Victoria, British Columbia, $93 \mathrm{p}$.

Timberline (2009) Installation and remeasurement of permanent sample plots: 2009 year end report, Unpublished report for the Soil and Vegetation Working Group of the Cumulative Environmental Management Association (CEMA), Fort McMurray, Alberta, $15 \mathrm{p}$.

Tongway, D.J. and Ludwig, J.A. (2011) Restoring disturbed landscapes putting principles into practice, Society for Ecological Restoration and Island Press. 